Alma Mater Studiorum - Università di Bologna DEPARTMENT OF ECONOMICS

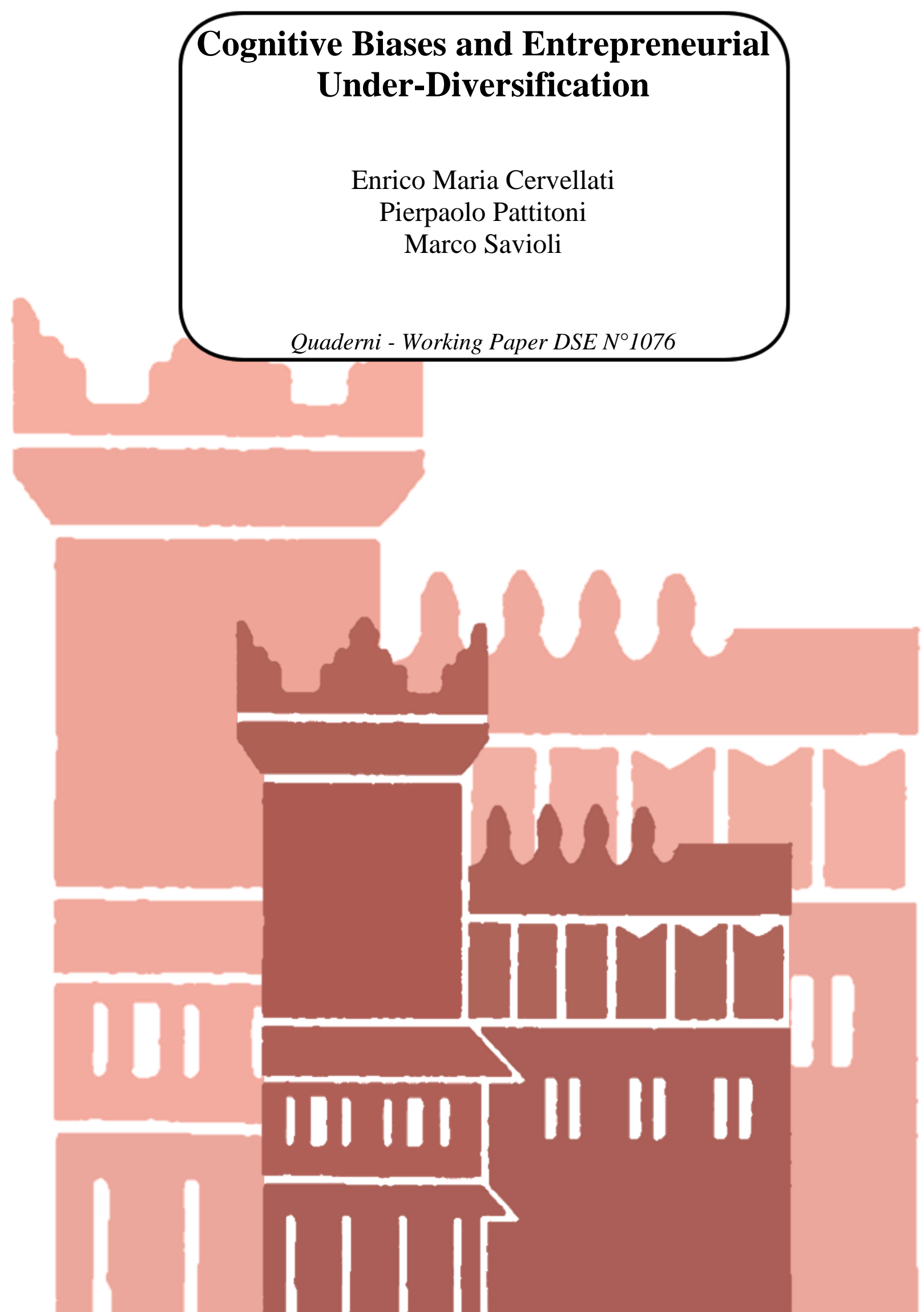




\title{
Cognitive Biases and Entrepreneurial Under-Diversification
}

\author{
Enrico Maria Cervellatia*, Pierpaolo Pattitoniac, Marco Savioli ${ }^{\text {bc }}$
}

\begin{abstract}
Cognitive biases lead entrepreneurs to overinvest in their own companies, over exposing themselves to idiosyncratic risk. Our novel theoretical model explains entrepreneurial underdiversification by measuring the amount of potential bias in entrepreneurs' portfolio allocations brought about by overconfidence and over optimism. Simulation analyses based on our model allow us calculating the implicit levels of overconfidence and over optimism from observable portfolio choices. Finally, using a unique dataset including cross-regional data on Italian entrepreneurs and a structural equation modeling approach, we test the effect of overconfidence and over optimism on entrepreneurs' portfolio allocations. Consistent with our theoretical predictions, we find a positive relationship between overconfidence and entrepreneur investments in their own companies. On the other hand, the role of over optimism seems to be negligible.
\end{abstract}

Keywords: Cognitive Biases, Entrepreneurship, Portfolio Optimization, Simulation Analysis, Under-diversification, Structural Equation Models

JEL Classification: G02, G11, L26

a Department of Management - University of Bologna

Via Capo di Lucca, 34 - 40126 Bologna (BO) Italy

Phone: +390512098103 - Fax: +39051246411

E-mails: enrico.cervellati@unibo.it; pierpaolo.pattitoni@unibo.it

${ }^{b}$ Department of Economics - University of Bologna

Via Angherà, 22 - 47921 Rimini (RN) Italy

Phone: +390541 434148 - Fax: +390541 434120

E-mail: m.savioli@unibo.it

c The Rimini Centre for Economic Analysis, Italy

* Corresponding Author 


\section{Introduction}

Several empirical findings show that entrepreneurs often invest a large share of their personal wealth in their own companies, over exposing themselves to idiosyncratic risk because their stake in the company is higher than the one that a rational risk-return analysis would suggest (Heaton and Lucas, 2000; Moskowitz and Vissing-Jørgensen, 2002). As Müller (2011, p. 545) notes:

Owners of private companies typically have a high share of their personal net worth invested in a single private company. The large investments give them high ownership shares, which reduces agency costs, but also exposes them to the idiosyncratic risk of the company.

This exposure to idiosyncratic risk can be very costly (Kerins et al., 2004; Pattitoni et al., 2013). Since some studies point out that entrepreneurs demand compensation for their exposure to idiosyncratic risk (Müller, 2011), one possible explanation for this puzzling evidence - i.e., that entrepreneurs 'do not understand' idiosyncratic risk - can be ruled out. ${ }^{1}$ Other justifications mostly rely on non-pecuniary benefits such as achieving greater control over their work environment: entrepreneurs obtain substantial rewards from being their own boss and, thus, they are willing to accept a suboptimal risk-return trade-off (Puri and Robinson, 2008; Ødegaard, 2009; Puri and Robinson, 2009; Shefrin, 2011). An alternative explanation is that entrepreneurs may invest in what they think they know better (Vardas and Xepapadeas 2012). Despite these justifications, it is still debated why entrepreneurs overinvest in their own company given the suboptimal risk-return trade-off. As Moskowitz and Vissing-Jørgensen (2002, p. 774) point out:

\footnotetext{
${ }^{1}$ For a study that analyses the role of bounded rationality in investment decisions, see Magni (2009).
} 


\section{[...] it seems surprising that entrepreneurs are willing to invest so heavily in a single private firm which offers a far worse risk-return trade-off.}

While the behavioral approach has been extensively used in the field of corporate finance (e.g., managerial overconfidence), or with regard to individual or professional investors (Glaser and Weber, 2007; Broihanne et al., 2014), there are still few theoretical studies in the behavioral economics literature with specific reference to the entrepreneurship field (Yazdipour, 2011). We intend to fill this gap, proposing a theoretical framework that proves how cognitive biases may explain the decision to become entrepreneur or to continue overinvesting in their already existing companies.

We focus on overconfidence and over optimism as two of the most prominent examples of cognitive biases. While overconfidence generally leads entrepreneurs to underestimate the risk on the investment in their own companies, over optimism typically causes them to overvalue its return. Thus, it is likely that both behavioral biases would lead entrepreneurs to overinvest in their companies (Shefrin, 2011).

With regard to risk underestimation caused by overconfidence, we refer to Slovic's and Olsen's notion of perceived risk (Slovic, 1987, 2000; Olsen, 2011) and to the 'twocomponent' total perceived risk formula proposed by Yazdipour $(2011){ }^{2}$ We include their framework within a theoretical model that distinguishes between the objective component of entrepreneurs' own companies expected returns and the over optimistic component that leads to overestimate these returns. It is worth noting that with over optimism, we refer to unrealistic optimism as a domain-specific bias in expectations (Weinstein 1980), rather than to dispositional optimism, i.e., the positive personality trait by which a person holds positive generalized expectations regarding the future (Scheier and Carver, 1985).

\footnotetext{
2 Yazdipour (2011) distinguishes between the objective ('resident risk') and subjective ('behavioral') components of risk
} 
We consider both overconfidence and over optimism as parameters in our model, and show how they may affect a risk-return analyses à la Markowitz (Markowitz, 1952, 1959). Through this parameterization, we measure the potential bias in entrepreneurs' portfolio allocations brought about by overconfidence and/or over optimism, thus explaining entrepreneurial under-diversification. Indeed, under-diversification is an important and wellknown issue for entrepreneurs and investors, which has both micro- and macro-level implications (James et al., 2012). Using a simulation analysis, we calculate how distinct parameters of overconfidence and over optimism affect entrepreneurs' portfolio choices. Our simulations also allow calculating the overconfidence and over optimism levels that, given a set of assumptions on the model parameters, are implicit in observable portfolio choices.

Then, using a unique dataset including cross-regional data on entrepreneurs in Italy - an ideal setting for our analysis given its "entrepreneurial vocation" - and a structural equation modeling approach, we test our theoretical predictions on cognitive biases and entrepreneur investments.

The paper is organized as follows. Section 2 proposes our theoretical model and simulation analysis. Section 3 presents our empirical analysis and interprets the main findings. Section 4 provides some policy suggestions and concluding remarks.

\section{Theoretical setup}

In this section we propose our theoretical model, which aims at explaining how cognitive biases, and more specifically overconfidence and over optimism, may lead entrepreneurs to overinvest in their own companies. In particular, we consider an entrepreneur that has to choose her portfolio allocation, i.e., which part of her wealth to invest in her own company and which to invest in the stock market. This portfolio optimization problem is dual: either 
the entrepreneur minimizes the risk for a given portfolio expected return, or she maximizes the return for a given portfolio risk (Ingersoll, 1987). In the following section, we discuss the impact of overconfidence on risk minimization, as the literature suggests that the former is likely to bias risk perceptions (Simon et al., 2000). Then, we focus on the impact of over optimism on return maximization, given the relationship between over optimism and perceived expected returns (De Meza and Southey, 1996).

\subsection{Overconfidence}

\subsubsection{Risk minimization}

Consider an entrepreneur who holds a portfolio composed of two risky assets with weights $\boldsymbol{\omega}=\left[\omega_{I}, \omega_{M}\right]^{\prime}$ and a risk free asset with weight $\omega_{F}$. Asset $I$ is the entrepreneur investment in her own company, while asset $M$ is the entrepreneur investment in a well-diversified stock market portfolio.

The excess return of the entrepreneur's portfolio can be expressed by $\mu_{P}=\boldsymbol{\omega}^{\prime} \boldsymbol{\mu}$, where $\boldsymbol{\mu}=\left[\mu_{I}, \mu_{M}\right]$ is the vector of the excess returns over the risk free rate $r_{F}$. The portfolio variance is given by $\sigma_{P}^{2}=\boldsymbol{\omega}^{\prime} \boldsymbol{\Sigma} \boldsymbol{\omega}$, where $\boldsymbol{\Sigma}=\left[\begin{array}{cc}\sigma_{I}^{2} & \sigma_{I M} \\ \sigma_{I M} & \sigma_{M}^{2}\end{array}\right]$ represents the positive-definite variance-covariance matrix of the returns of risky assets with $\operatorname{det} \boldsymbol{\Sigma}=\sigma_{I}^{2} \sigma_{M}^{2}-\sigma_{I M}^{2}>0$.

For a given value of portfolio expected excess return, $\mu_{P}=k$, the entrepreneur prefers the portfolio with the lowest variance. She faces the problem 
$\left\{\begin{array}{l}\min \omega^{\prime} \Sigma \boldsymbol{\omega} \\ \boldsymbol{\omega}^{\prime} \boldsymbol{\mu}=k\end{array}\right.$

Note that the constraint $\omega_{I}+\omega_{M}+\omega_{F}=1$ is implicit in $\boldsymbol{\omega}^{\prime} \boldsymbol{\mu}=k$.

Setting up the Lagrangian and solving the problem (Pattitoni and Savioli, 2011), the optimal portfolio weights are

$\boldsymbol{\omega}(k)=\frac{k \boldsymbol{\Sigma}^{-1} \boldsymbol{\mu}}{\boldsymbol{\mu}^{\prime} \boldsymbol{\Sigma}^{-1} \boldsymbol{\mu}}$

The first element of $\omega(k)$ represents the weight in the private company, namely

$$
\begin{aligned}
\omega_{I}(k) & =\frac{k\left(\sigma_{M}^{2} \mu_{I}-\rho_{I M} \sigma_{I} \sigma_{M} \mu_{M}\right)}{\sigma_{M}^{2} \mu_{I}^{2}-2 \rho_{I M} \sigma_{I} \sigma_{M} \mu_{I} \mu_{M}+\sigma_{I}^{2} \mu_{M}^{2}} \\
& =\frac{k \sigma_{M}^{2} \alpha}{\sigma_{M}^{2} \mu_{I}^{2}-2 \rho_{I M} \sigma_{I} \sigma_{M} \mu_{I} \mu_{M}+\sigma_{I}^{2} \mu_{M}^{2}}
\end{aligned}
$$

where $\rho_{I M}=\sigma_{I M} /\left(\sigma_{I} \sigma_{M}\right)$ and $\alpha$ is the Jensen's alpha, i.e. $\alpha=\mu_{I}-\rho_{I M}\left(\sigma_{I} / \sigma_{M}\right) \mu_{M}$.

\subsubsection{Overconfidence-driven under-diversification}

Now we analyze how overconfidence may influence the entrepreneur's weight in her own company. As noted above, overconfidence causes the entrepreneur to undervalue the actual risk of the investment in her own company. In this case, the biased standard deviation of the 
company returns, indicated by $\tilde{\sigma}_{I}{ }^{3}$ is lower than the actual standard deviation, i.e., $\tilde{\sigma}_{I}<\sigma_{I}$ ${ }^{4}$ We model $\tilde{\sigma}_{I}$ as

$$
\tilde{\sigma}_{I}=\sigma_{I}\left(1-\delta_{C}\right) \quad \delta_{C} \in[0,1)
$$

where $\delta_{C}$ is the overconfidence parameter, ranging from 0 (no overconfidence) to 1 (maximum overconfidence). ${ }^{5}$ When $\delta_{C}$ tends to 1 , then $\tilde{\sigma}_{I}$ tends to zero. To analyze the impact on the portfolio weight in the private company caused by overconfidence, we define $\tilde{\omega}_{I}(k)$ as $\omega_{I}(k)$ in Equation (3) with $\tilde{\sigma}_{I}$ in place of $\sigma_{I}$, i.e., with biased standard deviation instead of the rational one, to take into account that overconfident entrepreneurs tend to underestimate the risk of their companies.

We then consider two cases: first, the private company and market portfolio returns are uncorrelated; second, they are correlated either negatively or positively.

\section{Case 1: Uncorrelated returns $\left(\rho_{I M}=0\right)$}

Assuming a null correlation between the private company and market portfolio returns is similar to assuming that the private company's economic situation is (mostly) not affected by the economic contingency (Pattitoni et al., 2013). While not fully realistic, this assumption might be plausible for new ventures operating in innovative industries and has the advantage of greatly simplifying analytical derivations. The main result when the private company and market returns are uncorrelated is that the overconfident entrepreneur tends to overinvest in

\footnotetext{
${ }^{3}$ From now on, the tilde over a symbol (e.g., $\tilde{\sigma}_{I}$ ) indicates a biased parameter or variable.

${ }^{4}$ Since the covariance between the private company returns and the market returns is given by $\sigma_{M}=\rho_{I M} \sigma_{I} \sigma_{M}$, if the perceived standard deviation of the company returns, $\tilde{\sigma}_{I}$, differs from the actual one, $\sigma_{I}$, then overconfidence leads to a biased perception of the covariance, $\tilde{\sigma}_{I M}$.

${ }^{5}$ Choosing $\delta_{C} \in(-\infty, 1)$, we would allow for underconfidence.
} 
her own company and to be under-diversified, $\partial \tilde{\omega}_{I}(k) / \partial \delta_{C}>0$. The overconfidence bias is thus positive and equal to

$b_{c}=\tilde{\omega}_{I}(k)-\omega_{I}(k)>0$

Case 2: Correlated returns $\left(\rho_{I M} \neq 0\right)$

Consider now the case when the private company and market returns are correlated. Using the definition of $\tilde{\omega}_{I}(k)$, we get the partial derivative

$$
\frac{\partial \tilde{\omega}_{I}(k)}{\partial \delta_{C}}=\frac{k \sigma_{I} \sigma_{M} \mu_{M}\left\lfloor 2 \sigma_{I}\left(1-\delta_{C}\right) \sigma_{M} \mu_{I} \mu_{M}-\rho_{I M} \sigma_{M}^{2} \mu_{I}^{2}-\rho_{I M} \sigma_{I}^{2}\left(1-\delta_{C}\right)^{2} \mu_{M}^{2}\right]}{\left[\sigma_{M}^{2} \mu_{I}^{2}-2 \rho_{I M} \sigma_{I}\left(1-\delta_{C}\right) \sigma_{M} \mu_{I} \mu_{M}+\sigma_{I}^{2}\left(1-\delta_{C}\right)^{2} \mu_{M}^{2}\right]^{2}}
$$

Looking at Equation (6), we can conveniently divide our analysis in two subcases.

\section{Case 2.1 Negatively correlated returns $\left(\rho_{I M}<0\right)$}

When the private company and market portfolio returns are negatively correlated (e.g., the private company operates in a countercyclical industry), then it is easy to show that $\partial \tilde{\omega}_{I}(k) / \partial \delta_{C}>0$. Therefore, the result in Equation (5) continues to hold, i.e., the entrepreneur underestimates the risk of her own company and overinvest in it.

\section{Case 2.2 Positively correlated returns $\left(\rho_{I M}>0\right)$}

When the private company and market portfolio returns are positively correlated (i.e., the private company operates in a cyclical industry), the sign of $\partial \widetilde{\omega}_{I}(k) / \partial \delta_{C}$ is not 
straightforward. Imposing the condition $\partial \tilde{\omega}_{I}(k) / \partial \delta_{C}=0$, we find two stationary points. In the space $\left(\delta_{C}, \tilde{\omega}_{I}\right)$, the coordinates of these two points are

$$
\begin{aligned}
& \left(\delta_{C}^{-}, \tilde{\omega}_{I}^{-}\right)=\left(1-\frac{\mu_{I}}{\mu_{I}-\alpha}\left(1+\sqrt{1-\rho_{I M}^{2}}\right), \frac{k}{2 \mu_{I}} \frac{\rho_{I M}^{2}}{-\sqrt{1-\rho_{I M}^{2}}-\left(1-\rho_{I M}^{2}\right)}\right) \\
& \left(\delta_{C}^{+}, \tilde{\omega}_{I}^{+}\right)=\left(1-\frac{\mu_{I}}{\mu_{I}-\alpha}\left(1-\sqrt{1-\rho_{I M}^{2}}\right), \frac{k}{2 \mu_{I}} \frac{\rho_{I M}^{2}}{\sqrt{1-\rho_{I M}^{2}}-\left(1-\rho_{I M}^{2}\right)}\right)
\end{aligned}
$$

Since $\left(\delta_{C}^{-}, \tilde{\omega}_{I}^{-}\right)$is a minimum and $\left(\delta_{C}^{+}, \tilde{\omega}_{I}^{+}\right)$is a maximum, $\partial \tilde{\omega}_{I}(k) / \partial \delta_{C}>0$ in the interval $\left(\delta_{C}^{-}, \delta_{C}^{+}\right)$, and $\partial \tilde{\omega}_{I}(k) / \partial \delta_{C} \leq 0$ elsewhere.

We notice that $\alpha>0$ is a sufficient condition for $\delta_{C}^{-}<0$ to hold. ${ }^{6}$ However, we assume $\delta_{C} \in[0,1)$. Thus, $\tilde{\omega}_{I}$ reaches its minimum when $\delta_{C}=0$ and $\tilde{\omega}_{I}=\omega_{I}$.

On the other hand, when overconfidence approaches its limiting value (i.e., $\delta_{C} \rightarrow 1$ ), we find a particular weight

$$
\lim _{\delta_{C} \rightarrow 1} \tilde{\omega}_{I}(k)=\frac{k}{\mu_{I}}
$$

When $\delta_{C} \in\left(\delta_{C}^{+}, 1\right), \partial \widetilde{\omega}_{I}(k) / \partial \delta_{C}<0$. In this case, the entrepreneur invests so much in her own company that, to meet the constraints of the portfolio selection problem, the weight in the

\footnotetext{
${ }^{6} \alpha>0$ is a prerequisite to justify investments in private companies because it can be interpreted as a positive Net Present Value (NPV > 0). If financial markets are efficient, then positive NPV investments are feasible only for real investment projects (e.g., investing in the entrepreneur's private company), and not for financial investment projects, for which the NPV should be zero.
} 
well-diversified market portfolio needs to be negative, ${ }^{7}$ i.e., she should sell the market portfolio short. However, we can consider short selling of the market portfolio as not significant from an economic point of view. Thus, excluding this extreme case, ${ }^{8}$ there is no ambiguity on the sign of the derivative, and we may conclude that, in general, overconfidence leads to overinvestment in the entrepreneur's own company and to portfolio underdiversification. Figure 1 offers a graphical representation of all the aforementioned results.

\section{[Insert Figure 1 about here]}

To analyze the effect of overconfidence more in depth, a point worth noting is that overconfidence implies not only suboptimal portfolio weights but also a biased perception of portfolio risk. Since the perceived private company risk decreases with the level of overconfidence (i.e., $\partial \tilde{\sigma}_{I} / \partial \delta_{C}=-\sigma_{I}<0$ ), whenever the perceived portfolio risk increases with the perceived private company risk (i.e., $\partial \widetilde{\sigma}_{P} / \partial \tilde{\sigma}_{I}>0$ ) and overconfidence leads to overinvest in the company (i.e., $\left.\partial \tilde{\omega}_{I}(k) / \partial \delta_{C}>0\right),{ }^{9}$ then it follows that $\partial \tilde{\omega}_{I}(k) / \partial \tilde{\sigma}_{P}=\left(\partial \tilde{\omega}_{I}(k) / \partial \delta_{C}\right)\left(\partial \delta_{C} / \partial \tilde{\sigma}_{I}\right)\left(\partial \tilde{\sigma}_{I} / \partial \tilde{\sigma}_{P}\right)<0$.

\footnotetext{
${ }^{7}$ Using the constraint in the problem (1), we get $\tilde{\omega}_{M}=\left(k-\tilde{\omega}_{I} \mu_{I}\right) / \mu_{M}$. Therefore, when overconfidence reaches its limiting value and $\tilde{\omega}_{I}(k)=k / \mu_{I}$, then $\tilde{\omega}_{M}=0$. When $\tilde{\omega}_{I}(k)>k / \mu_{I}$, as happens for $\delta_{c} \in\left(\delta_{c}^{+}, 1\right)$, then $\tilde{\omega}_{M}<0$. Imposing $\tilde{\omega}_{M} \geq 0$ means that only corner solutions are possible, where the maximum weight that the overconfident entrepreneur may invest in her company is given by $\tilde{\omega}_{I}(k)=k / \mu_{I}$. Thus, the overconfident entrepreneur may even be frustrated by not being able, without short selling the market portfolio, to invest the desired amount of wealth in her private company.

${ }^{8}$ In this extreme case, $\tilde{\omega}_{I}(k)>0, \tilde{\omega}_{M}<0$, and $\rho_{I M}>0$. Since the portfolio variance is given by the formula $\tilde{\omega}_{I}^{2} \sigma_{I}^{2}\left(1-\delta_{C}\right)^{2}+2 \tilde{\omega}_{I} \tilde{\omega}_{M} \rho_{I M} \sigma_{I}\left(1-\delta_{C}\right) \sigma_{M}+\tilde{\omega}_{M}^{2} \sigma_{M}^{2}$, following an increase in $\delta_{C}$, the change in the contribution of the covariance term (the second term in the expression) to the portfolio variance is positive and dominates the change in the contribution of the variance term (the first term in the expression), which is negative. Thus, the higher the overconfidence, the higher the perceived portfolio risk for a given $\widetilde{\omega}_{I}$ and, thus, the lower the $\widetilde{\omega}_{I}$ chosen by the entrepreneur. Of course, this case is at the opposite of what previous studies have shown, i.e., that overconfidence leads to underestimation of risk. We can consider this extreme case as not significant from a theoretical point of view.

${ }^{9}$ That is the most common case. Conversely, in case 2.2, when $\delta_{c} \in\left(\delta_{c}^{+}, 1\right)$ (i.e., when the entrepreneur should sell the market portfolio short), $\partial \tilde{\sigma}_{P} / \partial \tilde{\sigma}_{I}<0$ but also $\partial \tilde{\omega}_{I}(k) / \partial \delta_{C}<0$. Therefore, the inequality $\partial \tilde{\omega}_{I}(k) / \partial \tilde{\sigma}_{P}<0$ still holds.
} 
To clarify this result Figure 2 shows the link between the perceived frontier of investments (the dashed line) and the weight in the entrepreneur's own company.

[Insert Figure 2 about here]

The first plot in Figure 2 shows the shift in the frontier caused by overconfidence, while the second one projects this shift in the private company weight. Note that the slope of the curve in the second plot is determined by $\partial \widetilde{\omega}_{I}(k) / \partial \widetilde{\sigma}_{P}$.

All the aforementioned results describe the effects of under evaluating the actual risk due to overconfidence and are summed up in the following observation.

Observation 1. Typically, overconfidence leads the entrepreneur to overinvest in her company, $\partial \widetilde{\omega}_{I}(k) / \partial \delta_{C}>0$, and to under-diversify her portfolio. The only case in which $\partial \tilde{\omega}_{I}(k) / \partial \delta_{C}<0$ occurs is when $\rho_{I M}>0$ and the level of overconfidence is particularly high, $\delta_{C} \in\left(\delta_{C}^{+}, 1\right)$.

From the previous observation, the first testable hypothesis follows.

H1. The entrepreneur investment in her own company has a positive relation with her level of overconfidence.

\subsection{Over optimism}

Since overconfidence affects risk perception, we studied its effect on portfolio risk using a risk minimization approach, which keeps the expected return level fixed. In the following, we analyze the effect of over optimism on portfolio expected return using a return maximization approach, which holds the objective risk constant. 
Figure 3 shows the duality of the problem showing the tangency conditions that identify lower iso-risk (left plot) and upper iso-return (right plot).

[Insert Figure 3 about here]

\subsubsection{Return maximization}

The duality of the problem allows considering return maximization as the solution for the entrepreneur's optimization problem for a given value of portfolio risk, $\sigma_{P}^{2}=s^{2}$. In such a setting, the entrepreneur faces the problem

$$
\left\{\begin{array}{l}
\max \boldsymbol{\omega}^{\prime} \boldsymbol{\mu} \\
\boldsymbol{\omega}^{\prime} \boldsymbol{\Sigma} \boldsymbol{\omega}=s^{2}
\end{array}\right.
$$

Setting up the Lagrangian and solving the problem, the optimal portfolio weights are ${ }^{10}$

$$
\boldsymbol{\omega}(s)=\frac{s \boldsymbol{\Sigma}^{-1} \boldsymbol{\mu}}{\left(\boldsymbol{\mu}^{\prime} \boldsymbol{\Sigma}^{-1} \boldsymbol{\mu}\right)^{\frac{1}{2}}}
$$

The weight in the private company is

$$
\begin{aligned}
\omega_{I}(s) & =\frac{s\left(\sigma_{M}^{2} \mu_{I}-\sigma_{I M} \mu_{M}\right)}{\left[\left(\sigma_{I}^{2} \sigma_{M}^{2}-\sigma_{I M}^{2}\right)\left(\sigma_{M}^{2} \mu_{I}^{2}-2 \sigma_{I M} \mu_{I} \mu_{M}+\sigma_{I}^{2} \mu_{M}^{2}\right)\right]^{\frac{1}{2}}} \\
& =\frac{s \sigma_{M}^{2} \alpha}{\left[\left(\sigma_{I}^{2} \sigma_{M}^{2}-\sigma_{I M}^{2}\right)\left(\sigma_{M}^{2} \mu_{I}^{2}-2 \sigma_{I M} \mu_{I} \mu_{M}+\sigma_{I}^{2} \mu_{M}^{2}\right)\right]^{\frac{1}{2}}}
\end{aligned}
$$

${ }^{10}$ As the problem is quadratic, we also obtain a second solution with weights equal to minus those of Equation (10). We discard them since they are dominated $\left(\alpha>0 \Rightarrow \omega_{I}(s)>0\right)$. 


\subsubsection{Over optimism-driven under-diversification}

As we mention above, over optimism causes the entrepreneur to overestimate the actual return of the investment in her own company. In this case, the biased expected return, indicated by $\tilde{\mu}_{I}$, is larger than the actual expected return, i.e., $\tilde{\mu}_{I}>\mu_{I}$.

We model $\tilde{\mu}_{I}$ as

$\tilde{\mu}_{I}=\frac{\mu_{I}}{1-\delta_{O}} \quad \delta_{O} \in[0,1)$

where $\delta_{O}$ is the over optimism parameter, which ranges from 0 (no over optimism) to 1 (maximum over optimism). When $\delta_{O}$ tends to 1 , then $\tilde{\mu}_{I}$ tends to infinity. ${ }^{11}$ Note that the justifications of entrepreneur's under-diversification based on non-pecuniary benefits as the desire for control can be modeled by varying $\mu_{I}$ as well. In that case, the 'biased' $\mu_{I}$ would incorporate, after an opportune normalization, the value of non-pecuniary benefits. Thus our model can simultaneously take into account the case of under-diversification brought about by over optimism and/or non-pecuniary benefits.

In order to see the variation of the portfolio weight in her own company in case of over optimism, we define $\tilde{\omega}_{I}(s)$ as the $\omega_{I}(s)$ in Equation (11) with $\tilde{\mu}_{I}$ in place of $\mu_{I}$, to underline that over optimistic entrepreneurs will overestimate future expected returns from their company. Using this definition, we get the partial derivative

\footnotetext{
${ }^{11}$ Choosing $\delta_{o} \in(-\infty, 1)$, we would allow for under optimism.
} 


$$
\frac{\partial \tilde{\omega}_{I}(s)}{\partial \delta_{O}}=\frac{s \frac{\mu_{I}}{\left(1-\delta_{O}\right)^{2}} \mu_{M}^{2}\left(\sigma_{I}^{2} \sigma_{M}^{2}-\sigma_{I M}^{2}\right)^{\frac{1}{2}}}{\left[\sigma_{M}^{2} \frac{\mu_{I}^{2}}{\left(1-\delta_{O}\right)^{2}}-2 \sigma_{I M} \frac{\mu_{I}}{\left(1-\delta_{O}\right)} \mu_{M}+\sigma_{I}^{2} \mu_{M}^{2}\right]^{\frac{3}{2}}}
$$

Since $\partial \tilde{\omega}_{I}(s) / \partial \delta_{O}>0$, the over optimist entrepreneur tends to overinvest in her own company and to be under-diversified. The over optimism bias is

$$
b_{o}=\tilde{\omega}_{I}(s)-\omega_{I}(s)>0
$$

The limit case for over optimism identifies a particular weight

$$
\lim _{\delta_{O} \rightarrow 1} \tilde{\omega}_{I}(s)=\frac{s \sigma_{M}}{\left(\sigma_{I}^{2} \sigma_{M}^{2}-\sigma_{I M}^{2}\right)^{\frac{1}{2}}}
$$

Similar to overconfidence, a point worth noting is that over optimism implies not only suboptimal portfolio weights but also a biased perception of portfolio return. Since the perceived portfolio return increases with the perceived private company return (i.e., $\left.\partial \tilde{\mu}_{P} / \partial \tilde{\mu}_{I}>0\right)$, the perceived private company return increases with the level of over optimism (i.e., $\partial \tilde{\mu}_{I} / \partial \delta_{O}=\mu_{I} /\left(1-\delta_{O}\right)^{2}>0$ ), as well as the weight in the private company (i.e., $\left.\quad \partial \tilde{\omega}_{I}(s) / \partial \delta_{O}>0\right)$. Then, $\quad$ it follows that $\partial \tilde{\omega}_{I}(s) / \partial \tilde{\mu}_{p}=\left(\partial \tilde{\omega}_{I}(s) / \partial \delta_{O}\right)\left(\partial \delta_{O} / \partial \tilde{\mu}_{I}\right)\left(\partial \tilde{\mu}_{I} / \partial \tilde{\mu}_{P}\right)>0$

This result is clearly presented in Figure 4, which shows the link between the perceived frontier of investments (dashed) and the weight in the private company. 
[Insert Figure 4 about here]

The plot on the right of Figure 4 shows the shift in the frontier caused by over optimism; the plot on the left projects this shift on the private company weight. Note that the slope of the curve in the plot on the left is determined, as explained above, by $\partial \tilde{\omega}_{I}(s) / \partial \tilde{\mu}_{p}$.

All the aforementioned results describe the effects of the overestimation of the actual return due to over optimism and can be summarized in the following observation.

Observation 2. Over optimism always leads to overinvestment in the entrepreneur's own company, $\partial \tilde{\omega}_{I}(s) / \partial \delta_{O}>0$, and to portfolio underdiversification.

From the previous observation, the second testable hypothesis follows.

H2. The entrepreneur investment in her own company has a positive relation with her level of over optimism.

\subsection{Implicit overconfidence and over optimism levels}

To understand the effects of overconfidence and over optimism on the weight invested by the entrepreneur in her company, we consider a couple of numerical examples. Using the estimates in tables 2 and 4 of Kerins et al. (2004) who analyzed a sample of IPOs in technologically-oriented industries, we choose the following set of parameters: $\sigma_{I}=1.204$, $\sigma_{M}=0.162, \rho_{I M}=0.195, \mu_{I}=0.535$, and $\mu_{M}=0.06$. We set $k=0.300$ and implicitly determine $s=0.566$. 
Based on this set of parameters, in Table 1 , we show $\widetilde{\omega}_{I}, \widetilde{\omega}_{M}$, and $\widetilde{\omega}_{F}$ by varying the level of overconfidence (Panel A) or the level of over optimism (Panel B).

\section{[Insert Table 1 about here]}

For moderate levels of overconfidence, an increase in $\delta_{C}$ leads to an increase in $\widetilde{\omega}_{I}$. Note that even low levels of overconfidence cause a severe overinvestment in the private company (e.g., when $\delta_{C}=0.2$, the weight in the private company is about $20 \%$ larger than it should be if the entrepreneur was not overconfident). ${ }^{12}$ When the level of overconfidence tends to its limiting value (i.e., $\delta_{C} \rightarrow 1$ ), $\widetilde{\omega}_{I}=0.561$ and $\widetilde{\omega}_{M}=0$. When $\widetilde{\omega}_{I}>0.561$ (i.e., when $\delta_{C}$ is about 0.8), $\widetilde{\omega}_{M}<0$, implying that the entrepreneur is short selling the market portfolio. When selling short is not allowed, $\widetilde{\omega}_{I}$ is thus equal to 0.561 .

Considering the over optimism bias, we note that, as with the case of overconfidence, for particularly high levels of over optimism (e.g., $\delta_{O} \cong 0.8$ or higher), $\widetilde{\omega}_{M}<0$. Differently from what happens in case of overconfidence, an increase in $\delta_{O}$ always causes an increase in $\widetilde{\omega}_{I}$. It is worth underlining that, in this numerical example, overconfidence leads to higher overinvestment in the company, compared to over optimism. ${ }^{13}$

Since the value of $\sigma_{I}$ in the previous numerical example is particularly high, as Kerins et al. (2004) referred to companies going public before and during the Internet bubble, in Table 2 we present another numerical example using a new set of parameters that we may consider as an 'average case'.

\footnotetext{
12 This result comes from the comparison between the values assumed by $\tilde{\omega}_{I}$ when $\delta_{C}$ varies. When $\delta_{C}=0$, $\tilde{\omega}_{I}=0.343$. When $\delta_{C}=0.2, \tilde{\omega}_{I}=0.412$. Then, the percentage change is $(0.412-0.343) / 0.343=20.12 \%$.

${ }^{13}$ We can prove this claim calculating the percentage change in $\tilde{\omega}_{I}$ when $\delta_{O}$ varies, and showing that is lower than the ones calculated above for $\delta_{C}$.
} 
[Insert Table 2 about here]

In particular, we choose $\sigma_{I}=0.40, \sigma_{M}=0.20, \rho_{I M}=0.20, \mu_{I}=0.15, \mu_{M}=0.06$, $k=0.12$, and $s=0.273$. Even if the latter results quantitatively differ from the ones in Table 1, we notice that their qualitative pattern does not change using this new set of parameters.

Note that, if we assume that our model is sufficiently adequate to describe entrepreneurs' portfolio choices under overconfidence and/or over optimism, we can also analyze Tables 1 and 2 with a "bottom-up" perspective to calculate the 'implicit' overconfidence and over optimism levels given a set of parameters and an observed $\widetilde{\omega}_{I}$. For example, based on Table 1 - Panel A (i.e., using a risk minimization perspective with $k=0.300$ ), after observing $\widetilde{\omega}_{I}=0.480$, we can conclude that $\delta_{C}=0.4$. Calculating the implicit overconfidence and over optimism levels is useful to determine how these behavioral biases may affect entrepreneurial decisions. In other words, not only the presence of these biases, but also their magnitude impacts the entrepreneurs' portfolio weight in their own companies and, consequently, the level of idiosyncratic risk they bear due to sub-optimal decisions in portfolio formation.

\section{Empirical analysis}

In this section, we empirically test $\mathrm{H} 1$ and $\mathrm{H} 2$ using a structural equation modeling (SEM) approach. In the following subsections, we describe our unique dataset and variables. Then, we present our main results and robustness checks.

\subsection{Sample and data}

We test $\mathrm{H} 1$ and $\mathrm{H} 2$ using a dataset obtained from the Italian Association of Insurance Firms (ANIA, Associazione Nazionale delle Imprese Assicurative, 2010). In 2008-2009, ANIA 
gathered information on 2,295 Italian Small and Medium Enterprises (SMEs, i.e., firms with less than 250 employees $)^{14}$ through a survey administered to entrepreneurs and divided in two parts: questionnaires and direct interviews.

Entrepreneurs were first asked to fill in a questionnaire containing data on the insurance coverage and other data related to their firm. Then, they were directly interviewed to gather additional (personal) information. Thus, a unique feature of this dataset is that it combines entrepreneurs' personal information and data on their companies. We have data on the fraction of entrepreneurs' total wealth invested in their own company. On average, the entrepreneurs in our sample invest almost half of their total wealth in their company. This choice may lead them to bear too much idiosyncratic risk that eventually may be transferred to their household, and affect their wealth. While questionnaires were meant to gather data on the firms, with special regard to insurance decisions and access to credit, the direct interviews were intended to gather entrepreneurs' personal information. The dataset includes entrepreneurs' demographic characteristics, but also data regarding their families, such as the household wealth, but also on personal insurance contracts, etcetera. In addition, some questions were intentionally thought to detect the entrepreneurs' behaviors, and eventually to spot behavioral biases. Answers to these questions provide information not only on overconfidence and over optimism, but also on ambiguity aversion, regret aversion, etcetera.

After deleting observations with missing values, the total number of observations is 1,613.

\footnotetext{
${ }^{14}$ Firms in our sample are quite young (average firm age is around 34 years) and small (with revenues generally below 10 million euros and with an average number of employees of 31). More information on the dataset can be found in ANIA (2010).
} 


\subsection{Measures}

We present a list of the variables we use in our empirical analysis. While in this section we mainly focus on the economic rationale of choosing these variables, in Table A1 in the Appendix we provide a detailed description of their construction.

The dependent variable in our models, $\omega$, measures the share of the entrepreneurs' own wealth invested in her company. The entrepreneur's wealth is defined as the sum of the investments in the company and financial market.

Based on our theoretical model, we include in our empirical models several variables that may exert an influence on $\omega$. These variables indicate whether the company has branches abroad, the region and the sector in which the company operates. They are specifically meant to proxy for risk-return variables ${ }^{15}$ (correlations, volatilities, expected returns) that are unobservable for private companies, but geographic and sector specific, and that, together with overconfidence and over optimism, should influence $\omega$.

Then, we consider a variable measuring entrepreneurs' attitude toward risk that we built using answers to a specific question asked during the interview with the entrepreneur. The question asked entrepreneurs which one of the following four states of the world they would prefer: "Very high profits with really high risk of loss", "Good profits and high risk of loss", "Normal profits with low risk of loss", and finally "Low profits with no risk of loss". More than half of entrepreneurs (almost 1,200 out of 2,295) preferred the first state of the world, i.e., "Normal profit, with low risk of loss", and more than a third (almost 800 respondents) choose the second one, i.e., "Good profit, and high risk of loss", while only about $10 \%$ of entrepreneurs admitted to choose the less risky possibility, i.e., "Low profit, no risk of loss".

\footnotetext{
15 Similar to other studies (Pattitoni et al., 2013), the implicit assumption here is that Italian firms within the same region-industry cluster share similarities in terms of risk-return characteristics.
} 
To create our measure of overconfidence we use five variables indicating entrepreneurs' dedication to their work (Schaufeli et al., 2002), height (Graham et al., 2013), gender (Barber and Odean, 2001), degree of perseverance (Clark and Friesen, 2009) and the degree to which they consider themselves better than average ('Better Than Average effect', BTA; Hoelzl and Rustichini, 2005). In particular, dedication is measured in terms of number of hours after which the entrepreneur states she would rather stop working to do something else, perseverance reflects whether she immediately or never gives up in difficult times (intermediate responses are admitted), and BTA measures if she perceives her abilities and knowledge to be above or below the average with respect to other entrepreneurs.

To create our measure of over optimism, we use four variables indicating the entrepreneur's perception of the probability of having accidents or causing damages (see Luppi and Parisi, 2009 and the references therein) both compared to the industry average, whether they save funds to deal with emergencies, and their expectations in life (Dawson and Henley, 2012). The latter variable measures the so-called "Rose-Colored Glasses" (RCG) effect (Lovallo and Kahneman, 2003). In particular, entrepreneurs were asked if they expect more good than bad things in life (intermediate responses are admitted).

In Table 3, we present descriptive statistics revealing that on average entrepreneurs in our sample invest almost half of their total wealth in their own company and that the majority of the companies have no branches abroad. The most represented regions are Lombardy and Emilia Romagna, two of the most productive regions in Italy, both accounting for $16.4 \%$ of the firms in the sample. On the other hand, the most represented sectors are Manufacturing (30.6\%) and Trade, Hotels and Restaurants $(25.5 \%) .{ }^{16}$ Also in this respect, our sample is representative of the Italian reality where manufacturing and tourism services are prominent

\footnotetext{
16 The "Building Construction" sector accounts for less than $10 \%$ of the total, while the Mining Industry, Transportation, Energy, Water and ICT each account for less than $5 \%$. The remain $25 \%$ of firms are from different sectors related to other services.
} 
among SMEs. Entrepreneurs in our sample are mostly male, tend to be slightly conservative about risk, dedicated to their companies, perseverant and perceive themselves to be above average with respect to other entrepreneurs. On average, they tend to deem the probability of having accidents or causing damages to be lower than their peers. Really few entrepreneurs (less than $30 \%$ of the total) save funds for emergencies, ${ }^{17}$ while they have positive expectations on life.

[Insert Table 3 about here]

\subsection{Results}

Our empirical models aim at estimating the relationship between the entrepreneurs' own wealth invested in their company, overconfidence and over optimism. A crucial feature of our empirical models is that, while we can observe $\omega$, both overconfidence and over optimism are latent variables. To address the relationship between observable and latent variables, we use a SEM approach. A typical SEM framework can be divided into two parts: (i) a structural part, which accounts for the relationship between endogenous and exogenous variables (both of which can be observable or latent); and (ii) a measurement part, aimed at measuring latent variables. Results of SEM analyses are typically represented with path diagram.

Figure 5 shows standardized coefficients of our path diagram. While in the upper part of the figure, we show the structural relationships between $\omega$, latent and control variables, in the lower part, we measure overconfidence and over optimism. In the measurement part of the model, all loadings on our latent variables, enclosed in ovals, are significant. In the structural part, we find evidence in support of $\mathrm{H} 1$ as the effect of overconfidence on $\omega$ is positive and

\footnotetext{
17 Insurance contracts may be used as a substitute of emergency funds. However, we have evidence (not reported here for reasons of space) that the companies in our sample are dramatically under-insured.
} 
highly significant. However, in contrast with $\mathrm{H} 2$, over optimism seems not to affect the weight in the entrepreneur's own company. Consistent with findings of our simulation analysis, this result suggests the effect of overconfidence on $\omega$ dominates the effect of over optimism. Furthermore, the estimated covariance between our latent constructs, represented by a curved line in the figure, is not significant. As for the control variables, we find significant regional and industrial effects (in the figure we report joint tests of significance). This is an expected result since, as we mention above, these variables proxy for omitted variables that affect entrepreneurs' choices and that may be common across geographic and sector clusters. In addition, we find that entrepreneurs whose firms have no branches abroad invest more in their companies. Finally, risk attitude seems to negatively affect $\omega$. Although this results may appear counterintuitive, it may be that, similar to a form of "local bias", entrepreneurs perceive their companies as safe investments so that lower risk attitude implies high stakes in their companies.

\section{[Insert Figure 5 about here]}

To analyze the relationship between entrepreneur investments in their own companies and cognitive biases more in depth, Figure 6 shows the geographical representation of the regional averages of $\omega$ (left plot) and the predictions of overconfidence (central plot) and over optimism (right plot) based on the model in Figure 5. Darker colors indicate higher values of the corresponding variable. Even though the evidence is not clear cut, spatial clustering, maybe reflecting unobserved heterogeneity at regional level seems to characterize our variables. This unobserved heterogeneity is possibly brought about by structural risk-return characteristics of the firms that are omitted in the model, but controlled for by the inclusion of regional and industrial fixed effects.

[Insert Figure 6 about here] 
In Table 4, we present a few robustness checks (we omitted the measurement part of the models for brevity). An initial concern with our empirical analysis is that overconfidence and over optimism may be endogenous. Models 2, 3 and 4 take this potential endogeneity into account. In Model 2, we add $\omega$ to the equations of overconfidence and over optimism allowing for simultaneity between the two biases on one side and the share of the entrepreneurs' own wealth invested in her company on the other side. In Model 3, we consider a potential bidirectional feedback between overconfidence (which appears in the over optimism equation) and over optimism (which appears in the overconfidence equation). While in the model underlying Figure 5 (which is reported for reference in the first column of Table 4) we estimated the correlation between overconfidence and over optimism, in Model 3 the relationship between the latter two biases is assumed to be structural. Finally, in Model 4 we consider both simultaneity and bidirectional feedback between overconfidence and over optimism. Results suggest that the role of $\omega$ in modeling overconfidence and over optimism is negligible. In addition, excluding Model 3, where overconfidence seems to negatively influence over optimism, there are no other significant coefficients to report in the overconfidence and over optimism equations. On the other hand, after controlling for endogeneity and bidirectional feedback, some of the coefficients in the $\omega$ equation of Models 2, 3 and 4 become insignificant, possibly due to inefficiency brought about by the inclusions of irrelevant paths (the standard errors of Models 2 and 3 seem to be inflated if compared to those of Model 1). In the light of these results, we conclude that endogeneity is unlikely to play a major role in our empirical application or at least that its influence is not strong enough to invalidate inference based on simpler models.

A second concern with our analysis is the role of entrepreneur's height and gender in the reflective measurement model of overconfidence. Since height and gender are exogenous variables, directly including these two variables among the determinants of $\omega$ rather than 
using them as reflective indicators may seem more appropriate. Model 5 provides such an empirical test. While male entrepreneurs are found to invest more in their own companies, the results about the effects of overconfidence and over optimism on $\omega$ remain virtually unchanged.

Finally, Models 6, 7 and 8 present some sensitivity analyses excluding industrial fixed effects (Model 6), regional fixed effects (Model 7) or both (Model 8). Our results confirm those of Model 1, suggesting that the relationship between behavioral biases and $\omega$ is robust enough to withstand changes in the specification of the model.

\section{[Insert Table 4 about here]}

\section{Conclusions}

Previous findings in the literature show that entrepreneurs tend to overinvest in their own company, bearing higher levels of idiosyncratic risk, with respect to what would be optimal. We propose a possible explanation for this sub-optimal behavior, based on behavioral biases, that complements other explanations, which rely on non-pecuniary benefits, such as the entrepreneurs' desire of control.

We present a theoretical model that allows showing and measuring how overconfidence and over optimism affect the fundamental variables of the risk-return analysis $a ̀$ la Markowitz and lead entrepreneurs to overinvest in their own company and hold under-diversified portfolios. Overconfidence leads to underestimate the risk associated with the entrepreneur's own company, while over optimism to overestimate its expected return. Our model contributes to the literature on risk perception, but it could be extended to consider other motivations for the 
entrepreneurial behavior, such as the desire for control, since the latter, like over optimism, is likely to lead entrepreneurs to overestimate expected return on their own companies.

We perform simulation analyses to ascertain how much the entrepreneur's decision for investing in her own company is affected by variations in the two behavioral biases. As our theoretical model predicts, the entrepreneur invests more in her company as overconfidence and over optimism increase. The simulation can also be used, given other parameters and the weight in the private company, to calculate the implicit levels of entrepreneurial overconfidence and over optimism. Having an idea of the levels of overconfidence and over optimism may be useful to institutional investors when they have to choose which entrepreneurial projects to finance and for preliminary self-analysis by entrepreneurs.

Finally, using cross-regional data regarding 2,295 Italian SMEs we directly observe the share of entrepreneurs' total wealth invested in their own companies, and we use information on entrepreneurs' personal characteristics to discern how overconfidence and over optimism affect their choice on how much to invest in their companies. Using a SEM approach, our empirical results, corroborated by several robustness checks which allow us to increase the generalization potential of our analysis, suggest that overconfidence indeed leads entrepreneurs to invest more in their own companies, while the effect of over optimism is not statistically significant (simulation analyses further suggest that the effect of overconfidence dominates the effect of over optimism). Further research could expand these results by considering international settings. Although Italy is an ideal context for our empirical analysis due to its "entrepreneurial vocation", research on other countries could check for further implications of our theoretical model. These implications could be useful to stimulate further debate about the effects of cognitive biases on entrepreneurial choices. 


\section{References}

ANIA 2010. "La domanda di assicurazione delle imprese. Risultati dall'Indagine Ania sull'Assicurazione nelle Piccole Imprese Italiane"

Barber BM, Odean T. 2001. Boys will be boys: Gender, overconfidence, and common stock investment. Quarterly journal of Economics 116 (1): 261-292.

Broihanne MH, Merli M, Roger P. 2014. Overconfidence, risk perception and the risk-taking behavior of finance professionals. Finance Research Letters 11 (2): 64-73.

Clark J, Friesen L. 2009. Overconfidence in Forecasts of Own Performance: An Experimental Study. The Economic Journal 119 (534): 229-251.

Dawson C, Henley A. 2012. Something will turn up? Financial over-optimism and mortgage arrears. Economics Letters 117 (1): 49-52.

De Meza D, Southey C. 1996. The borrower's curse: optimism, finance and entrepreneurship. The Economic Journal 106 (435): 375-386.

Glaser M, Weber M. 2007. Why inexperienced investors do not learn: they do not know their past portfolio performance. Finance Research Letters 4 (4): 203-216.

Graham, JR, Campbell RH, and Puri M. 2013. Managerial Attitudes and Corporate Actions. Journal of Financial Economics 109: 103-121.

Heaton J, Lucas D. 2000. Portfolio choice and asset prices: the importance of entrepreneurial risk. The Journal of Finance 55 (3): 1163-1198.

Hoelzl E, Rustichini A. 2005. Overconfident: Do You Put Your Money On It?. The Economic Journal 115 (503): 305-318.

Ingersoll JE. 1987. Theory of financial decision making. Rowman \& Littlefield.

James J, Kasikov K, Edwards K-A. 2012. The end of diversification. Quantitative Finance 12 (11): 1629-1636.

Kerins F, Smith JK, Smith R. 2004. Opportunity cost of capital for venture capital investors and entrepreneurs. Journal of Financial and Quantitative Analysis 39 (2): 385-404.

Lovallo D, Kahneman D. 2003. Delusions of success. Harvard business review 81 (7): 5663.

Magni CA. 2009. Investment decisions, net present value and bounded rationality. Quantitative Finance 9 (8): 967-979.

Markowitz HM. 1952. Portfolio selection. The Journal of Finance 7 (1): 77-91. 1959. Portfolio selection: efficient diversification of investments. New York: John Wiley \& Sons.

Moskowitz TJ, and Vissing-Jørgensen A. 2002. The returns to entrepreneurial investment: a private equity premium puzzle? American Economic Review 92 (4): 745-778.

Müller E 2011. Returns to private equity: idiosyncratic risk does matter! Review of Finance 15 (3): $545-574$.

Ødegaard BA 2009. The diversification cost of large, concentrated equity stakes. How big is it? Is it justified? Finance Research Letters 6 (2): 56-72.

Olsen RA 2011. Financial risk perceptions: a behavioral perspective. In Advances in Entrepreneurial Finance, 45-67. New York: Springer.

Pattitoni P, Petracci B, Potì V, Spisni M. 2013. Cost of entrepreneurial capital and underdiversification: a Euro-Mediterranean perspective. Research in International Business and Finance 27 (1): 12-27.

Pattitoni P, Petracci B, Savioli M, Zirulia L. 2013. Entrepreneurial choice: A financial approach. Economia e Politica Industriale 40 (3): 71-91. 
Pattitoni P, Savioli M. 2011. Investment choices: indivisible non-marketable assets and suboptimal solutions. Economic Modelling 28 (6): 2387-2394.

Puri M, Robinson DT. 2008. Who are entrepreneurs and why do they behave that way? Working Paper. Durhum: Duke University.

2009. The economic psychology of entrepreneurship and family business. Working Paper. Durhum: Duke University.

Schaufeli WB, Salanova M, Gonzàlez-Romà V, Bakker AB. 2002. The measurement of engagement and burnout: a two sample confirmatory factor analytic approach. Journal of Happiness Studies 3: 71-92.

Scheier MF, Carver CS. 1985. Optimism, coping, and health: assessment and implications of generalized outcome expectancies. Health Psychology 4 (3): 219-247.

Shefrin H. 2011. Insights into the psychological profiles of entrepreneurs. In Advances in Entrepreneurial Finance, 173-181. New York: Springer.

Simon M, Houghton SM, Aquino K. 2000. Cognitive biases, risk perception, and venture formation: How individuals decide to start companies. Journal of business venturing 15 (2): 113-134.

Slovic P. 1987. Perception of risk. Science 236 (4799): 280-285.

- 2000. The perception of risk. London: Earthscan Publications.

Vardas G, Xepapadeas A. 2012. Uncertainty aversion, robust control and asset holdings. Quantitative Finance 0 (0): 1-15.

Weinstein ND. 1980. Unrealistic optimism about future life events. Journal of Personality and Social Psychology 39 (5): 806-820.

Yazdipour R. 2011. A behavioral finance approach to decision making in entrepreneurial finance. In Advances in Entrepreneurial Finance, 11-29. New York: Springer. 


\section{Appendix}

Table A1. Variable description

\begin{tabular}{|c|c|}
\hline \multirow{2}{*}{\multicolumn{2}{|c|}{$\begin{array}{l}\text { Variable } \\
\text { Structural }\end{array}$}} \\
\hline & \\
\hline$\omega$ & $\begin{array}{l}\text { This variable, which can range from } 0 \text { to } 1 \text {, indicates the share of the entrepreneur's } \\
\text { own wealth invested in her company. The entrepreneur's wealth is defined as the } \\
\text { sum of the investments in the company and financial market. }\end{array}$ \\
\hline Local & This is a dummy variable equal to 1 when a company has no branches abroad. \\
\hline Regions & $\begin{array}{l}\text { This is a set of } 20 \text { regional dummies. The two regions Piedmont and Aosta Valley } \\
\text { are pulled together since the latter is a small region, geographically close to } \\
\text { Piedmont. }\end{array}$ \\
\hline Industries & $\begin{array}{l}\text { This is a set of } 7 \text { dummies indicating the industry in which the entrepreneur } \\
\text { operates. }\end{array}$ \\
\hline Risk attitude & $\begin{array}{l}\text { This is a measure of entrepreneurs' attitude toward risk. Entrepreneurs were asked if } \\
\text { they would prefer: (4) "Very high profits and risk", (3) "Good profits and moderate } \\
\text { risk", (2) "Moderate profits and low risk", or (1) "Low profits and no risk". The } \\
\text { variable is normalized to the standard unit interval, with higher values indicating } \\
\text { greater attitude toward risk. }\end{array}$ \\
\hline \multicolumn{2}{|l|}{ Measurement } \\
\hline $\begin{array}{l}\text { Dedication } \\
(\log )\end{array}$ & $\begin{array}{l}\text { This is a measure of entrepreneurs' dedication. It is measured as the natural } \\
\text { logarithm of the number of hours after which the entrepreneur states she would } \\
\text { rather stop working to do something else. }\end{array}$ \\
\hline Heigh & atural logarithm of the entrepreneur's height in centimeters. \\
\hline Male & This is a dummy variable equal to 1 for male entrepreneurs. \\
\hline Perseverance & $\begin{array}{l}\text { This is a measure of entrepreneurs' perseverance. Entrepreneurs were asked if in } \\
\text { difficult times, they: }(0) \text { "immediately give up" or }(10) \text { "never give up". All } \\
\text { responses between } 0 \text { and } 10 \text { were accepted. The variable is normalized to the } \\
\text { standard unit interval, with higher values indicating greater perseverance. }\end{array}$ \\
\hline BTA & $\begin{array}{l}\text { This variable measures the "Better Than Average effect". Entrepreneurs were asked } \\
\text { if they perceive their abilities and knowledge to be above or below the average with } \\
\text { respect to other entrepreneurs. The variable is normalized to the standard unit } \\
\text { interval, with higher values indicating entrepreneurs more confident in their abilities } \\
\text { and knowledge. }\end{array}$ \\
\hline Accidents & $\begin{array}{l}\text { This is a measure of the entrepreneur's perception of the probability of having } \\
\text { accidents. Higher values indicate that the entrepreneur deems the probability of } \\
\text { having accidents lower than the average of other entrepreneurs operating in the } \\
\text { same industry. The variable is normalized to the standard unit interval. }\end{array}$ \\
\hline Damages & $\begin{array}{l}\text { This is a measure of the entrepreneur's perception of the probability of causing } \\
\text { damages. Higher values indicate that the entrepreneur deems the probability of } \\
\text { causing damages lower than the average of other entrepreneurs operating in the } \\
\text { same industry. The variable is normalized to the standard unit interval. }\end{array}$ \\
\hline $\begin{array}{l}\text { Emergencies } \\
\text { Funds }\end{array}$ & $\begin{array}{l}\text { This is a dummy variable equal to } 1 \text { if the entrepreneur does not set aside funds to } \\
\text { deal with emergencies. }\end{array}$ \\
\hline RCG & $\begin{array}{l}\text { This variable measures the "Rose-Colored Glasses" effect. Entrepreneurs were } \\
\text { asked if they expect more good things than bad things in life. The variable is } \\
\text { normalized to the standard unit interval, with higher values indicating greater } \\
\text { optimism. }\end{array}$ \\
\hline
\end{tabular}


Table 1. Implicit overconfidence and over optimism levels - parameters from Kerins et al. (2004)

Panel A - Overconfidence effects on risk minimization

\begin{tabular}{c|c|c|c|c|c|c}
\hline$\delta_{C}$ & 0.0 & 0.2 & 0.4 & 0.6 & 0.8 & $\cong 1.0$ \\
\hline$\tilde{\omega}_{I}$ & 0.343 & 0.412 & 0.480 & 0.534 & 0.563 & 0.561 \\
$\tilde{\omega}_{M}$ & 1.943 & 1.328 & 0.723 & 0.235 & -0.024 & 0.000 \\
$\tilde{\omega}_{F}$ & -1.286 & -0.740 & -0.203 & 0.230 & 0.461 & 0.439 \\
\hline$\tilde{\mu}_{P}$ & 0.300 & 0.300 & 0.300 & 0.300 & 0.300 & 0.300 \\
$\tilde{\sigma}_{P}$ & 0.566 & 0.487 & 0.387 & 0.267 & 0.135 & 0.000 \\
\hline
\end{tabular}

Panel B - Over optimism effects on return maximization

\begin{tabular}{c|c|c|c|c|c|c}
\hline$\delta_{O}$ & 0.0 & 0.2 & 0.4 & 0.6 & 0.8 & $\cong 1.0$ \\
\hline$\tilde{\omega}_{I}$ & 0.343 & 0.383 & 0.421 & 0.452 & 0.472 & 0.479 \\
$\tilde{\omega}_{M}$ & 1.943 & 1.544 & 1.058 & 0.498 & -0.103 & -0.694 \\
$\tilde{\omega}_{F}$ & -1.286 & -0.927 & -0.479 & 0.050 & 0.630 & 1.215 \\
\hline$\tilde{\mu}_{P}$ & 0.300 & 0.298 & 0.289 & 0.272 & 0.247 & 0.215 \\
$\tilde{\sigma}_{P}$ & 0.566 & 0.566 & 0.566 & 0.566 & 0.566 & 0.566 \\
\hline
\end{tabular}

Parameters

\begin{tabular}{c|c|c|c|c|c|c}
\hline$k$ & $s$ & $\mu_{I}$ & $\mu_{M}$ & $\sigma_{I}$ & $\sigma_{M}$ & $\rho_{I M}$ \\
\hline 0.300 & 0.566 & 0.535 & 0.06 & 1.204 & 0.162 & 0.195 \\
\hline
\end{tabular}


Table 2. Implicit overconfidence and over optimism levels - our assumptions

Panel A - Overconfidence effects on risk minimization

\begin{tabular}{c|c|c|c|c|c|c}
\hline$\delta_{C}$ & 0.0 & 0.2 & 0.4 & 0.6 & 0.8 & $\cong 1.0$ \\
\hline$\tilde{\omega}_{I}$ & 0.509 & 0.605 & 0.696 & 0.768 & 0.805 & 0.800 \\
$\widetilde{\omega}_{M}$ & 0.727 & 0.488 & 0.259 & 0.079 & -0.013 & 0.000 \\
$\tilde{\omega}_{F}$ & -0.236 & -0.093 & 0.045 & 0.153 & 0.208 & 0.200 \\
\hline$\tilde{\mu}_{P}$ & 0.120 & 0.120 & 0.120 & 0.120 & 0.120 & 0.120 \\
$\tilde{\sigma}_{P}$ & 0.273 & 0.234 & 0.185 & 0.127 & 0.064 & 0.000 \\
\hline
\end{tabular}

Panel B - Over optimism effects on return maximization

\begin{tabular}{c|c|c|c|c|c|c}
\hline$\delta_{O}$ & 0.0 & 0.2 & 0.4 & 0.6 & 0.8 & $\cong 1.0$ \\
\hline$\tilde{\omega}_{I}$ & 0.509 & 0.565 & 0.618 & 0.660 & 0.687 & 0.696 \\
$\tilde{\omega}_{M}$ & 0.727 & 0.571 & 0.383 & 0.169 & -0.057 & -0.278 \\
$\tilde{\omega}_{F}$ & -0.236 & -0.136 & 0.000 & 0.170 & 0.369 & 0.582 \\
\hline$\tilde{\mu}_{P}$ & 0.120 & 0.119 & 0.116 & 0.109 & 0.100 & 0.088 \\
$\tilde{\sigma}_{P}$ & 0.273 & 0.273 & 0.273 & 0.273 & 0.273 & 0.273 \\
\hline
\end{tabular}

Parameters

\begin{tabular}{c|c|c|c|c|c|c}
\hline$k$ & $s$ & $\mu_{I}$ & $\mu_{M}$ & $\sigma_{I}$ & $\sigma_{M}$ & $\rho_{I M}$ \\
\hline 0.120 & 0.273 & 0.150 & 0.060 & 0.400 & 0.200 & 0.200 \\
\hline
\end{tabular}


Table 3. Descriptive statistics

\begin{tabular}{|c|c|c|c|c|}
\hline Variable & Mean & SD & Min & Max \\
\hline \multicolumn{5}{|l|}{ Structural } \\
\hline$\omega$ & 0.479 & 0.340 & 0 & 1 \\
\hline Local & 0.944 & & & \\
\hline Regions: Piedmont and Aosta Valley & 0.082 & & & \\
\hline Lombardy & 0.164 & & & \\
\hline Trentino - South Tyrol & 0.001 & & & \\
\hline Veneto & 0.074 & & & \\
\hline Friuli - Venezia Giulia & 0.056 & & & \\
\hline Liguria & 0.043 & & & \\
\hline Emilia - Romagna & 0.164 & & & \\
\hline Tuscany & 0.096 & & & \\
\hline Umbria & 0.030 & & & \\
\hline Marche & 0.032 & & & \\
\hline Lazio & 0.043 & & & \\
\hline Abruzzo & 0.007 & & & \\
\hline Molise & 0.011 & & & \\
\hline Campania & 0.077 & & & \\
\hline Apulia & 0.058 & & & \\
\hline Basilicata & 0.001 & & & \\
\hline Calabria & 0.007 & & & \\
\hline Sicily & 0.030 & & & \\
\hline Sardinia & 0.025 & & & \\
\hline Industries: Mining & 0.027 & & & \\
\hline Manufacturing & 0.306 & & & \\
\hline Energy, water, telecommunications & 0.009 & & & \\
\hline Building & 0.089 & & & \\
\hline Trade, hotels and restaurants & 0.255 & & & \\
\hline Transportation & 0.044 & & & \\
\hline Other services & 0.270 & & & \\
\hline Risk attitude & 0.431 & 0.232 & 0 & 1 \\
\hline \multicolumn{5}{|l|}{ Measurement } \\
\hline Dedication (log) & 2.127 & 0.354 & 0 & 3.178 \\
\hline Height (log) & 5.149 & 0.048 & 4.997 & 5.298 \\
\hline Male & 0.666 & & & \\
\hline Perseverance & 0.789 & 0.165 & 0 & 1 \\
\hline BTA & 0.590 & 0.207 & 0 & 1 \\
\hline Accidents (higher values, lower probability) & 0.898 & 0.199 & 0 & 1 \\
\hline Damages (higher values, lower probability) & 0.903 & 0.198 & 0 & 1 \\
\hline Emergencies Funds ( 1 indicates no emergencies funds) & 0.725 & & & \\
\hline $\mathrm{RCG}$ & 0.725 & 0.177 & 0 & 1 \\
\hline
\end{tabular}

Source: our elaboration on data provided by ANIA (2010). Number of observations is 1,613. 
Table 4. Robustness checks

\begin{tabular}{|c|c|c|c|c|c|c|c|c|}
\hline Variable & (1) & (2) & (3) & (4) & (5) & (6) & (7) & (8) \\
\hline \multicolumn{9}{|c|}{ w equation } \\
\hline Overconfidence & $\begin{array}{c}0.078^{* * * *} \\
(0.030)\end{array}$ & $\begin{array}{c}0.045 \\
(0.104)\end{array}$ & $\begin{array}{c}0.078^{* * * *} \\
(0.030)\end{array}$ & $\begin{array}{c}0.276 \\
(0.267)\end{array}$ & $\begin{array}{l}0.084^{* *} \\
(0.041)\end{array}$ & $\begin{array}{c}0.080^{* * * *} \\
(0.030)\end{array}$ & $\begin{array}{l}0.078^{* *} \\
(0.031)\end{array}$ & $\begin{array}{l}0.079^{* *} \\
(0.031)\end{array}$ \\
\hline Over optimism & $\begin{array}{l}-0.043 \\
(0.033)\end{array}$ & $\begin{array}{l}-0.639 \\
(0.951)\end{array}$ & $\begin{array}{l}-0.043 \\
(0.033)\end{array}$ & $\begin{array}{l}-0.541 \\
(0.876)\end{array}$ & $\begin{array}{l}-0.054 \\
(0.033)\end{array}$ & $\begin{array}{l}-0.045 \\
(0.034)\end{array}$ & $\begin{array}{l}-0.042 \\
(0.033)\end{array}$ & $\begin{array}{c}-0.045 \\
(0.034)\end{array}$ \\
\hline Domestic & $\begin{array}{c}0.135^{\text {**** }} \\
(0.025)\end{array}$ & $\begin{array}{c}0.157^{* * * *} \\
(0.045)\end{array}$ & $\begin{array}{c}0.135^{* * * *} \\
(0.025)\end{array}$ & $\begin{array}{c}0.160^{* * * *} \\
(0.042)\end{array}$ & $\begin{array}{c}0.138^{* * * *} \\
(0.025)\end{array}$ & $\begin{array}{c}0.137^{\text {**** }} \\
(0.025)\end{array}$ & $\begin{array}{c}0.136^{* * * *} \\
(0.025)\end{array}$ & $\begin{array}{c}0.140^{* * * *} \\
(0.024)\end{array}$ \\
\hline Risk attitude & $\begin{array}{l}-0.045^{*} \\
(0.025)\end{array}$ & $\begin{array}{l}-0.089 \\
(0.080)\end{array}$ & $\begin{array}{l}-0.045^{*} \\
(0.025)\end{array}$ & $\begin{array}{l}-0.099 \\
(0.076)\end{array}$ & $\begin{array}{l}-0.048^{*} \\
(0.025)\end{array}$ & $\begin{array}{l}-0.047^{*} \\
(0.025)\end{array}$ & $\begin{array}{c}-0.049^{* * *} \\
(0.025)\end{array}$ & $\begin{array}{c}-0.050^{* * *} \\
(0.025)\end{array}$ \\
\hline $\begin{array}{l}\text { Height } \\
\text { Male }\end{array}$ & & & & & $\begin{array}{c}-0.029 \\
(0.032) \\
0.094^{* * *} \\
(0.031)\end{array}$ & & & \\
\hline Region fixed effects & Yes & Yes & Yes & Yes & Yes & Yes & No & No \\
\hline Industry fixed effects & Yes & Yes & Yes & Yes & Yes & No & Yes & No \\
\hline \multicolumn{9}{|c|}{ Overconfidence equation } \\
\hline$\omega$ & & $\begin{array}{c}0.037 \\
(0.105)\end{array}$ & & $\begin{array}{l}-0.202 \\
(0.437)\end{array}$ & & & & \\
\hline Over optimism & & & $\begin{array}{l}-0.009 \\
(0.039) \\
\end{array}$ & $\begin{array}{l}-0.025 \\
(0.557) \\
\end{array}$ & & & & \\
\hline \multicolumn{9}{|c|}{ Over optimism equation } \\
\hline$\omega$ & & $\begin{array}{c}0.629 \\
(0.938)\end{array}$ & & $\begin{array}{c}0.511 \\
(0.977)\end{array}$ & & & & \\
\hline Overconfidence & & & $\begin{array}{c}-0.004^{* *} \\
(0.002)\end{array}$ & $\begin{array}{l}-0.114 \\
(0.513)\end{array}$ & & & & \\
\hline
\end{tabular}

Significance levels: ${ }^{*} \mathrm{p}<0.10,{ }^{* *} \mathrm{p}<0.05,{ }^{* * *} \mathrm{p}<0.01$. The number of observations 1,613. All models include a constant. Standardized coefficients. Robust SEs in parenthesis. 
Figure 1. Private company weight in case of overconfidence

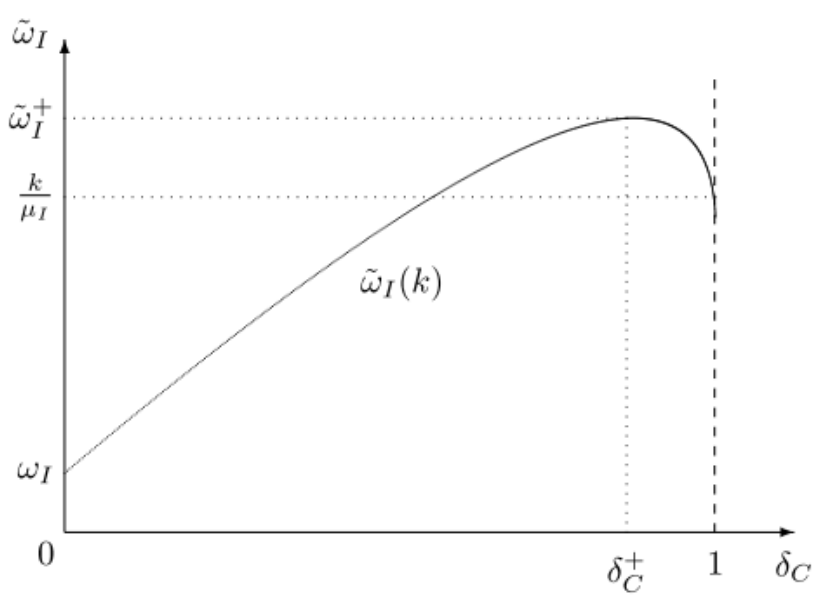

Figure 2. Frontier shift and overconfidence bias

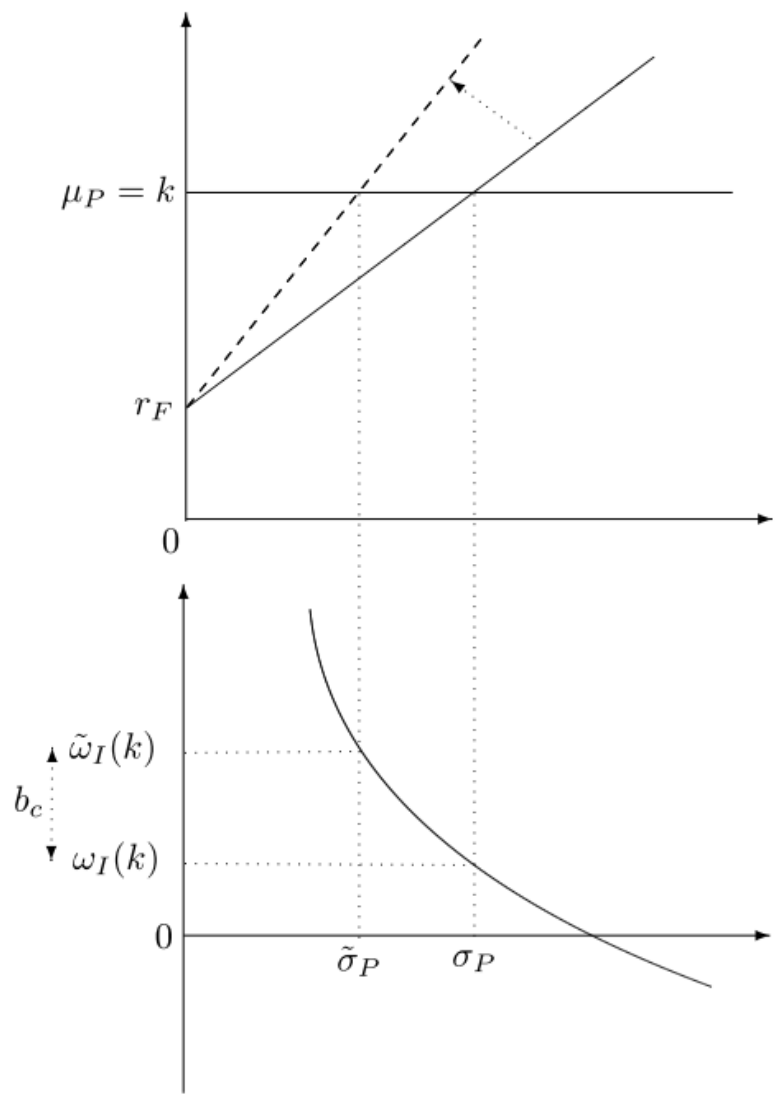


Figure 3. Duality in portfolio optimization
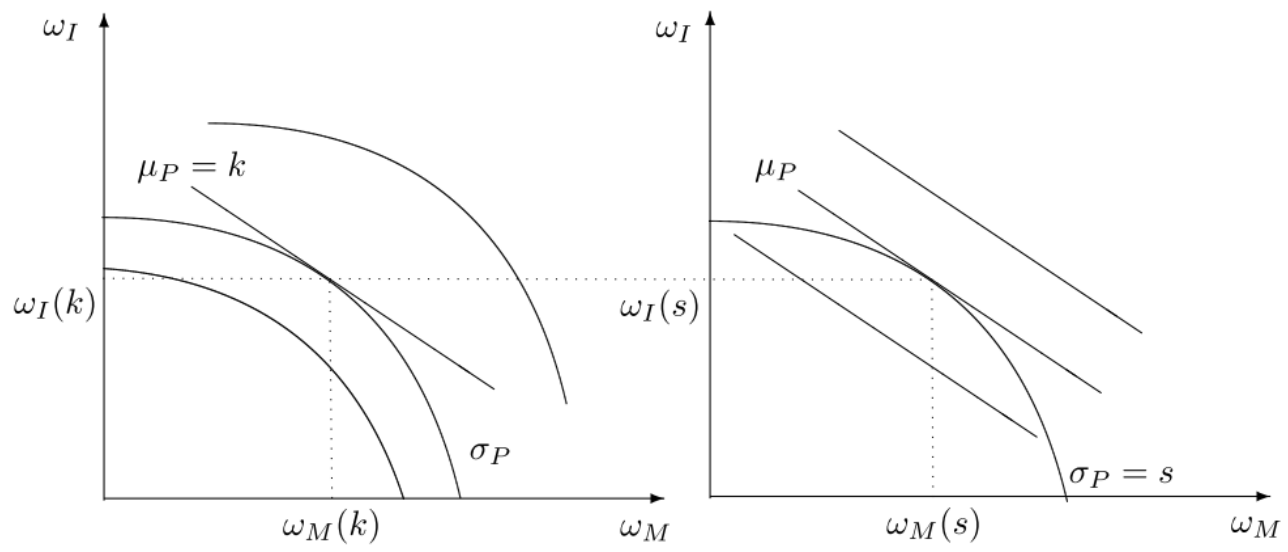

Figure 4. Frontier shift and over optimism bias.

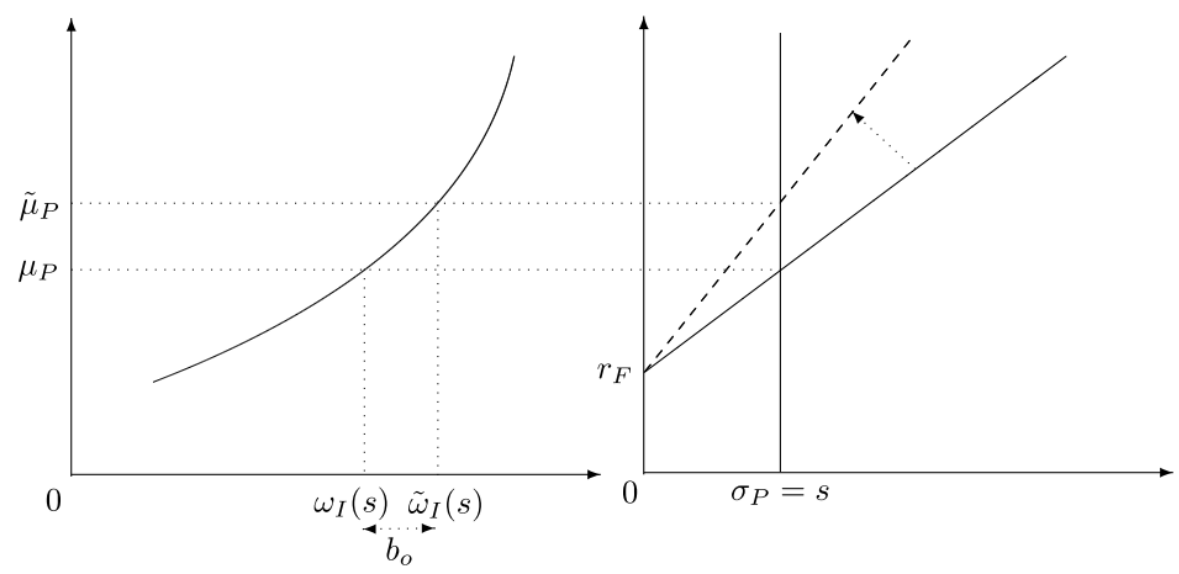


Figure 5. Estimated model

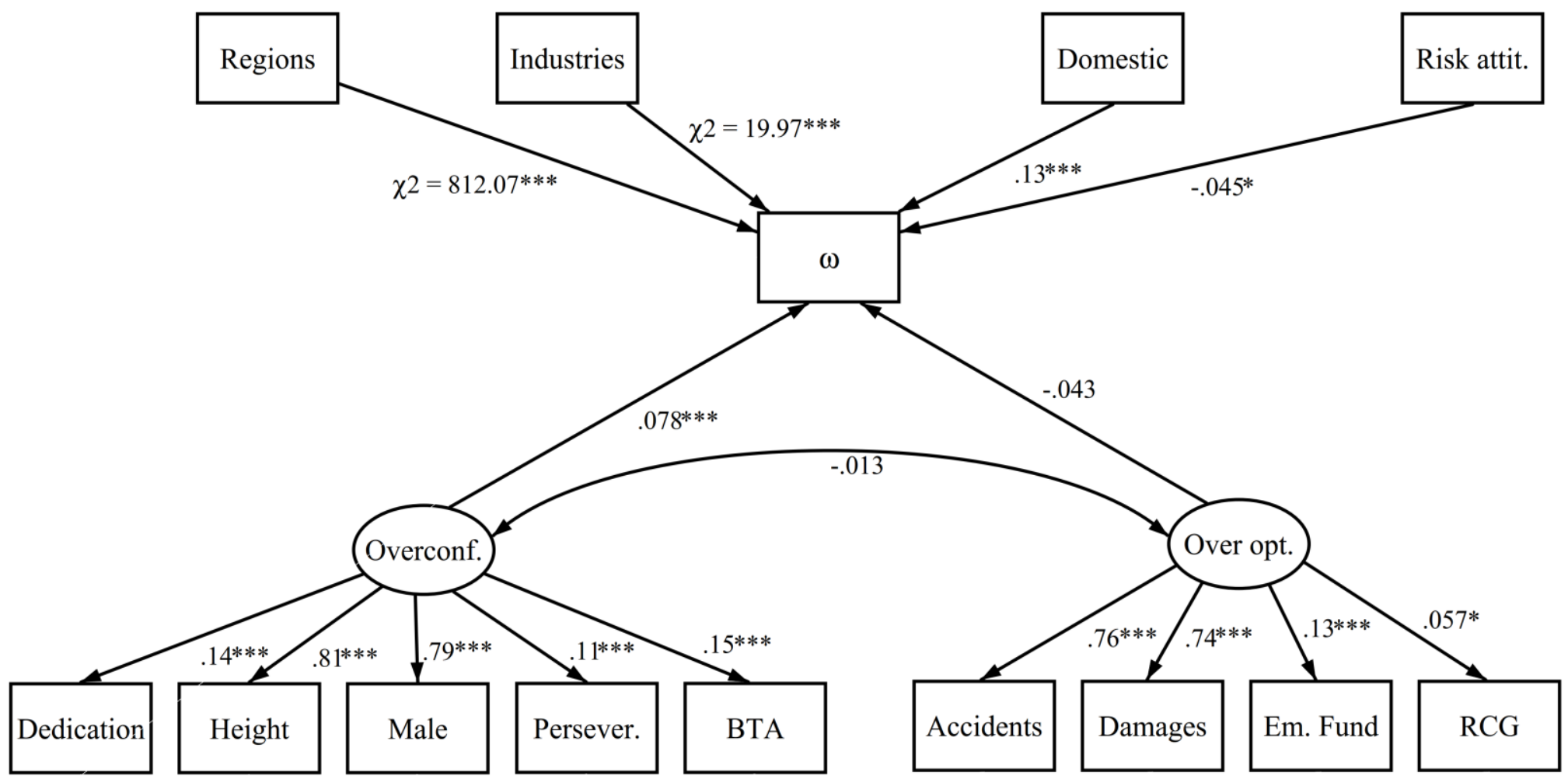

Significance levels: ${ }^{*} \mathrm{p}<0.10,{ }^{* *} \mathrm{p}<0.05,{ }^{* * *} \mathrm{p}<0.01$. The number of observations is equal to 1,613. All models include a constant. Standardized coefficients. 
Figure 6. Regional distribution of $\omega$, overconfidence and over optimism

Weight in the private company

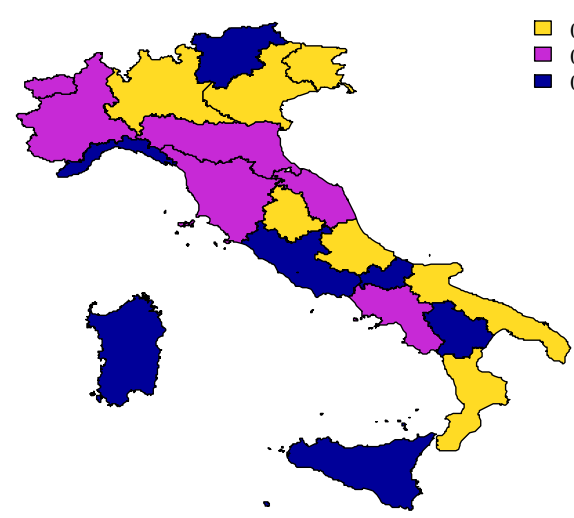

Overconfidence

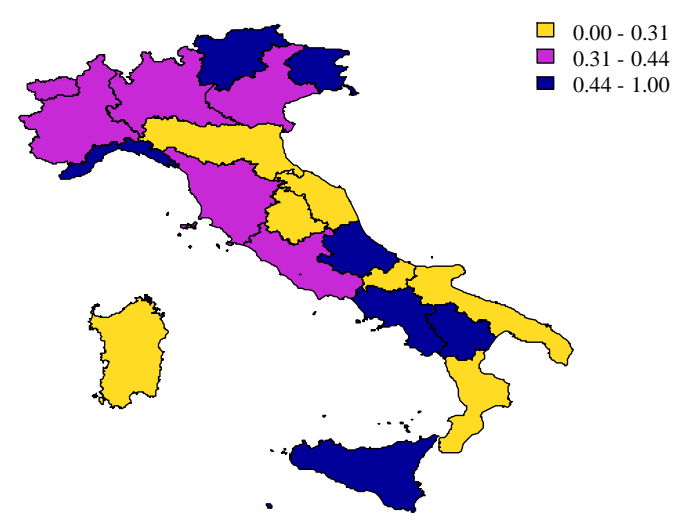

Over optimism

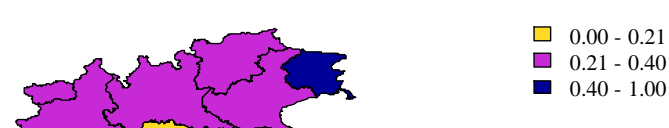

The map shows regional averages. Darker colors indicate higher values. Overconfidence and Over optimism are normalized to the standard unit interval. 


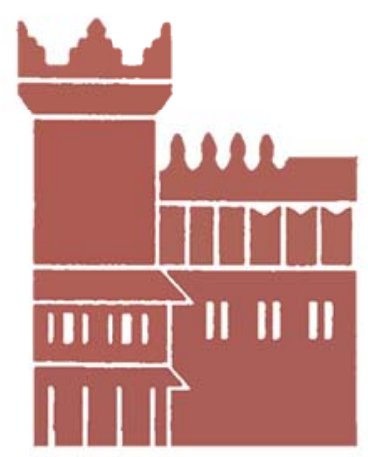

Alma Mater Studiorum - Università di Bologna DEPARTMENT OF ECONOMICS

Strada Maggiore 45

40125 Bologna - Italy

Tel. +39051 2092604

Fax +390512092664

http://www.dse.unibo.it 